\title{
A Working Threshold for Acute Nocturnal Melatonin Suppression from "White" Light Sources used in Architectural Applications
}

Mark S. Rea*1 and Mariana G. Figueiro ${ }^{1}$

Lighting Research Center, Rensselaer Polytechnic Institute, Troy, New York, USA

\begin{abstract}
Retinal light exposures can decrease melatonin production at night. Since nocturnal melatonin suppression by light has been implicated as an endocrine disruptor and linked to certain diseases, such as diabetes, obesity and cancer, it is important to be able to estimate a threshold light level needed to reliably suppress melatonin. The present study was designed to develop a working threshold for melatonin suppression from "white" light that might be experienced by people in their living environments. Twenty-eight subjects participated in two studies. In addition to dark, control nights, subjects were exposed to 8, 22, and 60 lux at the cornea (study 1, n=14) and to 60, 200, and 720 lux (study 2, n=14) of a "warm white" light source (correlated color temperature of $2670 \mathrm{~K}$ ). These corneal illuminance levels translate to modeled melatonin suppression levels of $1 \%, 2 \%, 6 \%, 19 \%$, and $42 \%$. In both studies, participants came to the laboratory for four nights, separated by one week. One blood sample was drawn in dim light at midnight and another blood sample was drawn after 60-minute exposure to each light condition (including dark). Using an orthodox statistical criterion for a Type I error of $\alpha<0.05$, only the 200 lux and the 720 lux exposures produced significant suppression levels (19\% and $37 \%$, respectively). Based upon a criterion modeled suppression level of $5 \%$ for a "cool white" light $(6500 \mathrm{~K})$, a corneal light exposure of 30 lux for 30 minutes from "white" light sources used in most architectural lighting applications is proposed as a conservative hypothesized working threshold for nocturnal melatonin suppression.
\end{abstract}

Keywords: Light at night; Melatonin; Phototransduction; Light emitting diodes; Circadian rhythms

\section{Introduction}

The master clock in the Suprachiasmatic Nuclei (SCN) in humans is genetically pre-programmed to cycle, on average, every 24.2 hours, although individuals differ in the precise timing of their master clock. For those who work during the day and sleep at night, the master clock is usually synchronized to local time by the light/dark patterns incident on the retina, despite those individual differences. In other words, the daily light/dark pattern provides synchronizing signals to the SCN, which then run on a 24 -hour schedule rather than on its preprogrammed period.

Exposure to bright electric lighting at night or dim electric lighting during the daytime, however, can affect the timing of SCN and, thus, circadian rhythms. Lighting technologies and applications for architectural spaces such as the home or the roadway are designed and built to support the human visual system, not our circadian system. Since the biophysical characteristics of light affecting our visual system are markedly different than those affecting our circadian system, exposure to electric lighting, day and night, may disrupt the natural 24-hour circadian cycle. Epidemiological studies have consistently shown, for example, that breast cancer is more likely to occur in nightshift-working women [1-4]. These women most likely experience circadian disruption because they are rarely exposed to a consistent light (at night) and dark (during the day) cycle. To estimate which light exposures throughout the solar day are and are not effective for stimulating the circadian system, it is necessary to characterize the spectral and absolute sensitivities of the human circadian system to retinal light exposures.

Retinal exposure to short-wavelength light of sufficiently high level and long duration will suppress nocturnal melatonin synthesis by the pineal gland via signal from the SCN; nocturnal melatonin suppression is an orthodox marker for circadian system stimulation by light [5-10].
A working threshold for acute melatonin suppression by light is not yet well accepted, however. Posture [11], photic history [12,13], biomarker type, methods for calculating acute melatonin suppression, the pulsatic nature of melatonin production [14], individual differences in preretinal filtering [15], and diet [16] are some of the reasons why it is difficult to define a value that might be taken as "the" threshold amount of light needed to suppress nocturnal melatonin. It is possible, however, to make predictions of the potential effectiveness of different light sources for reaching a criterion amount of nocturnal melatonin suppression using the model proposed by Rea et al. [6-7]. Consistent with published evidence from neurophysiology and neuro-anatomy, and from empirical data on light-induced nocturnal melatonin suppression in humans [8-10], the model incorporates the photopigment melanopsin contained in the Intrinsically-Photosensitive Retinal Ganglion Cells (ipRGCs) [17], as well as the photopigments in rods and cones. The peak spectral sensitivity of nocturnal melatonin suppression is shorter (close to $460 \mathrm{~nm}$ ) than the peak spectral response of melanopsin (close to $480 \mathrm{~nm}$ ) in humans. This observed phenomenon is consistent with the postulated retinal neural circuitry in the model whereby the ipRGCs receive depolarizing input from blue versus yellow (b-y) spectrally opponent retinal pathway [18].

Since the model provides quantitative estimates of nocturnal

*Corresponding authors: Mark S. Rea, PhD, Lighting Research Center, Rensselaer Polytechnic Institute, Troy, New York 12180, USA, Tel: 518687 7100; Fax: 518687 7120; E-mail: ream@rpi.edu

Received July 22, 2013; Accepted September 11, 2013; Published September 20, 2013

Citation: Rea MS, Figueiro MG (2013) A Working Threshold for Acute Nocturnal Melatonin Suppression from "White" Light Sources used in Architectural Applications. J Carcinogene Mutagene 4: 150. doi:10.4172/2157-2518.1000150

Copyright: (C) 2013 Rea MS, et al. This is an open-access article distributed under the terms of the Creative Commons Attribution License, which permits unrestricted use, distribution, and reproduction in any medium, provided the original author and source are credited. 
melatonin suppression following one-hour exposures during the early night to any light level or spectral composition, Figueiro et al. [19] proposed a working threshold for measurable melatonin suppression for white light sources commonly used in architectural applications, both indoors and outdoors. A criterion of $15 \%$ suppression was chosen, reflecting the $10 \%$ uncertainty in reliably measuring melatonin concentrations. This choice was made after examining data from several published studies of nocturnal melatonin suppression [20-22]. Figueiro et al. cautioned that this threshold value would vary for different individuals [23-25] and different spectral irradiance distributions [7], so a more cautious working threshold exposure of 30 lux of "white" light for 30 minutes was proposed [19].

The present study was designed to more closely examine the working threshold proposed by Figueiro et al. [19]. Nocturnal melatonin suppression was measured after one-hour exposures to a white light source of low Correlated Color Temperature (CCT), similar to incandescent lamps presently used in homes in North America, over a range of illumination levels that might be experienced in homes in North America. Based on model calculations, it was hypothesized that exposure to light levels below 30 lux would not result in melatonin suppression reliably different than zero, while the higher light levels could result in measureable suppression.

\section{Participants}

Twenty-eight subjects participated in two studies; each ran four consecutive weeks. Fourteen young adults, 7 males and 7 females (mean age \pm Standard Deviation $(\mathrm{SD})=21.4 \pm 1.5$ years), with a mean \pm SD reported chronotype [26] of $3.1 \pm 1.4$ participated in the first study. Fourteen young adults, 1 male and 13 females (mean age \pm $\mathrm{SD}=20.5 \pm 0.5$ years) with a mean \pm SD reported chronotype of $3.0 \pm$ 1.9 participated in the second. All subjects, by self-report, were nonsmokers, free from any major health problems, and were not taking any pharmaceuticals. None of the subjects travelled more than two time zones starting one month prior to the study. All subjects completed a consent form approved by Rensselaer's Institute Review Board and were paid for their participation.

\section{Light Sources}

Clear safety goggles were fitted with four Luxeon M3-PW71 (Philips Lumileds Lighting, San Jose, CA) "white" Light Emitting Diodes (LEDs), two per lens, to deliver the prescribed doses of light at the subjects' corneas. A potentiometer controlled current to the LEDs to adjust the light levels. The LEDs were covered with diffusing tape to reduce discomfort glare [27] and ensure that the maximum blue light hazard-weighted radiance [28] was below the safety threshold of $100 \mathrm{~W} /\left(\mathrm{m}^{2} \mathrm{sr}\right)$; the highest blue light hazard-weighted radiance at the highest current level used in the experiment was $1 \mathrm{~W} /\left(\mathrm{m}^{2} \mathrm{sr}\right)$ as measured with a Pritchard spectroradiometer (PR-705, Photo Research Inc., Chatsworth, CA). The spectral irradiance distribution (measured with an Oriel Instaspec IV spectrometer, Oriel Instruments, Stratford, $\mathrm{CT}$ ) of the light filtered through the diffusing tape (Figure 1) had a correlated color temperature (CCT) of $2670 \pm 29 \mathrm{~K}$.

\section{Light Doses}

In 2005, Rea and colleagues proposed a spectral sensitivity function for the human circadian system, followed by a model relating "Circadian Light" $\left(\mathrm{CL}_{\mathrm{A}}\right)$ to a quantity called "Circadian Stimulus" (CS) in $2010[7,29]$. CS should be directly proportional to light-induced nocturnal melatonin suppression, from below threshold to above

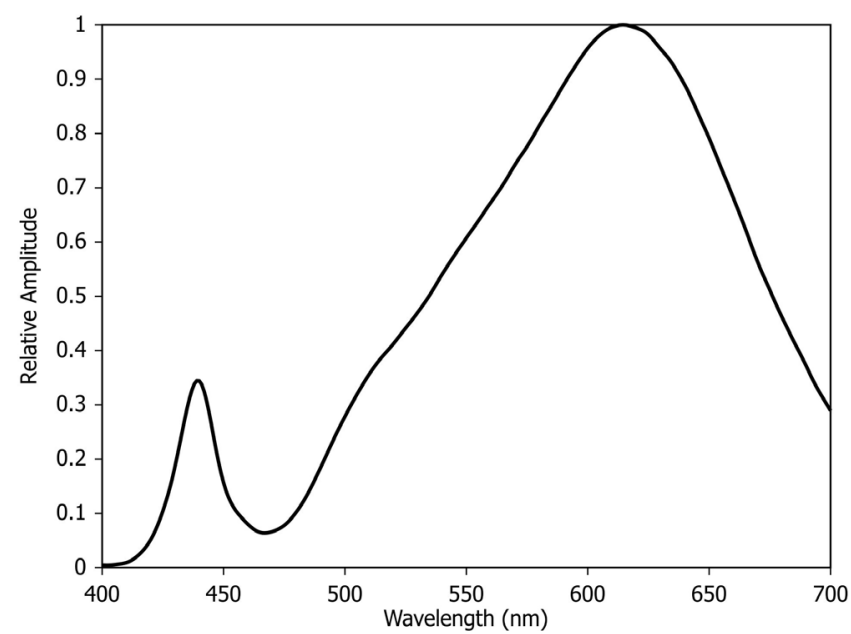

Figure 1: Average $(n=15)$ relative spectral irradiance distribution of light emitted from the goggles with the diffusing tape. The average CCT was $2670 \pm 29 \mathrm{~K}$. Measurements were of five goggles at 60 lux, five at 200 lux, and five at 720 lux.

\begin{tabular}{|c|c|c|c|c|}
\hline $\begin{array}{c}\text { Target } \\
\text { illuminance } \\
\text { (lux) }\end{array}$ & $\begin{array}{c}\text { Measured } \\
\text { illuminance (lux) }\end{array}$ & $\begin{array}{c}\text { Measured } \\
\text { irradiance (W/m2) }\end{array}$ & CLA & CS \\
\hline 8 & $8.15+/-0.12$ & $0.0252+/-0.00037$ & $\begin{array}{c}5.65+/- \\
0.085\end{array}$ & 0.7 \\
\hline 22 & $22.0+/-0.23$ & $0.0682+/-0.00071$ & $15.5+/-0.16$ & 2.2 \\
\hline 60 & $60.0+/-0.48$ & $0.190+/-0.0014$ & $42.4+/-0.34$ & 6.1 \\
\hline 200 & $200+/-1.5$ & $0.621+/-0040$ & $141+/-1.1$ & 19 \\
\hline 720 & $720+/-3.6$ & $2.23+/-0.010$ & $509+/-2.5$ & 42 \\
\hline
\end{tabular}

Table 1: Target (photopic) corneal illuminance levels (lux) used in the study together with the measured corneal illuminance (lux) and irradiance $\left(\mathrm{W} / \mathrm{m}^{2}\right)$ levels. Measured levels of Circadian Light $\left(\mathrm{CL}_{\mathrm{A}}\right)$ and consequent values of Circadian Stimulus (CS) from equation 1 are also shown.

saturation, for one-hour exposure during the middle of the subjective night. A fixed, $2.3 \mathrm{~mm}$ pupil diameter is assumed in the CS calculations. Thus, a calculated value of CS can be considered a predicted amount of nocturnal melatonin suppression resulting from a one-hour exposure to a light stimulus of a given $\mathrm{CL}_{\mathrm{A}}$. Values of CS range from 0 to 0.7 , representing light-induced nocturnal melatonin suppression from $0 \%$ to $70 \%$.

To account for newly published data on light-induced nocturnal melatonin suppression $[5,10]$ and a revised model of the spectral sensitivity of the human circadian system [6], the modeled relationship between CLA and CS was updated for the present study. The new formula for calculating CS from CLA utilizes the original two data sets, Brainard et al. [8] and Thapan et al. [9], and new data on light-induced nocturnal melatonin suppression from Brainard et al. [30], West et al. [10], and Figueiro et al. [5]. As with the original formulation, every corneal irradiance value in the updated data set was transformed into the updated values of CLA. A best-fitting sigmoid function, based upon the formulation used by Zeitzer et al. [31], was then determined to relate $\mathrm{CL}_{\mathrm{A}}$ to $\mathrm{CS}$ using a least-squares criterion. Again, CS is directly proportional to predicted levels of light-induced nocturnal melatonin suppression.

$$
C S=0.7 *\left(1-\frac{1}{1+\left(\frac{C L_{A}}{355.7}\right)^{1.1026}}\right)
$$

The target corneal illuminance levels chosen for study 1 were 8, 22, 
and 60 lux. The target corneal illuminance levels chosen for study 2 were 60, 200, and 720 lux. The target and measured illuminances and the measured irradiances are listed in Table 1, as well as the corresponding values of CS. Through the CS calculations (equation 1), the corneal illuminance levels translate to predicted melatonin suppression levels of $0.70 \%, 2.2 \%, 6.1 \%, 19 \%$, and $42 \%$, respectively. Both studies included a dark/control night. Each goggle set was calibrated using the Oriel Instaspec IV.

\section{Methods}

All participants were asked to maintain a regular sleep/wake cycle during the four weeks of the study. In addition to wearing actigraphs (Actiwatch-64, Mini-mitter, Bend, OR) on the non-dominant wrist, participants completed a sleep/wake diary for five weeks; during the study and one week prior to it. These diaries documented bedtimes, rising times, caffeine consumption, and quality of sleep during the weeks of the experiment. Sleep logs were verified with the wrist actigraph data. Subjects were asked not to consume any caffeine 12 hours prior to starting data collection on the day of the experiment

In each study, participants came to the laboratory for four nights, separated by one week. Every night they were asked to arrive at the laboratory at 23:30. The room lights were turned off and subjects remained in dim red light $(\lambda \max =630 \mathrm{~nm},<2$ lux at the cornea). Blood draws began at midnight (00:00) every study night; the light goggles were energized at 00:15 except on the baseline, dark night. At 01:15 another blood sample was drawn. Before the last blood draw, iris-pupil measurements were taken every study night with a Sony video camera and IMAQ Vision Builder software (version 6.1, National Instruments, Austin, TX) while the goggles were energized; no pupil measurements were taken during the dark night.

\section{Data Analyses}

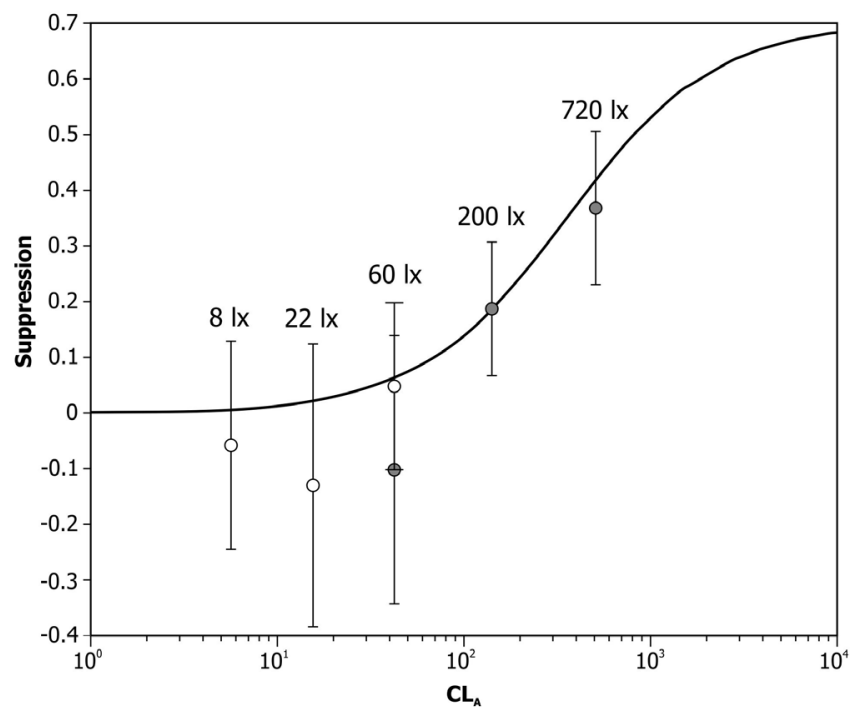

Figure 2: Mean nocturnal melatonin suppression and associated 95\% confidence intervals, for one-hour exposures of the $2670 \mathrm{~K}$ sources at different corneal illuminance (photopic lux) levels; open symbols are from the first study while closed symbols are from the second study. The continuous solid line represents the CS values for the white LED of $2670 \mathrm{~K}$ at different CLA levels according to equation 1 and the revised spectral sensitivity function for nocturnal melatonin suppression [6]. It should be noted that the functional relationship between CLA and CS is plotted without regard for the measured nocturnal melatonin suppression values obtained in the present study.
Plasma samples were assayed by radioimmunoassay using a commercially available kit (Labor Diagnostika Nord, Nordhorn, Germany). The limit of detection was $1.9 \mathrm{pg} / \mathrm{ml}$ and the intra- and inter-assay coefficients of variability were determined to be $11.4 \%$ and $12.7 \%$, respectively.

Adjusted dark values for each study $(A)$ were calculated for each subject to account for their natural rise in melatonin level concentrations (C) while in the dark and for differences in the initial melatonin concentrations week-to-week. Melatonin concentrations obtained from each subject during the initial dark condition $(D)$ at 00:00 were used for the adjusted dark values. Melatonin suppression was calculated for each lighting condition $\left(L_{\mathrm{m}}\right)$ using the adjusted dark value at the same sampling time $\left(T_{\mathrm{n}}\right)$. The adjusted dark value $(A)$ in a given study for a given lighting condition $(\mathrm{Lm})$ and sampling time $\left(T_{\mathrm{n}}\right)$ is given by:

$$
A=\left(C_{T 1, L m} / C_{T 1, D}\right) C_{T n, D}
$$

Where: $C=$ melatonin concentration $(\mathrm{pg} / \mathrm{ml})$

T=sampling time, $n=1,2$

$1=00: 00$ and $2=01: 15$

$L=$ lighting condition per study, $m=1,2,3$

In the first study: $1=8 \mathrm{~lx}, 2=22 \mathrm{~lx}, 3=60 \mathrm{~lx}$

In the second study: $1=60 \mathrm{~lx}, 2=200 \mathrm{~lx}, 3=720 \mathrm{~lx}$

$\mathrm{D}=$ dark

Melatonin suppression $(S)=100^{*}\left(1-\left[\mathrm{C}_{T n, L m} / A\right]\right)$

Two repeated measures, one factor (lighting conditions) analyses of variance (ANOVA) were performed using the melatonin suppressions obtained in both studies. Post hoc, two-tailed, onesample t-tests were also performed to determine whether melatonin suppression at each light level was significantly greater than zero. To reach statistical significance, the criterion probability of a Type 1 error (a) was set at 0.05 . All statistical analyses were performed using the PASW Statistics 18.0 (SPSS, Chicago, IL) software.

\section{Results}

The ANOVA using data from study 1 did not reveal a significant main effect of light level $\left(\mathrm{F}_{2,24}=1.9 ; \alpha=0.12\right)$. The ANOVA using data from study 2 revealed a significant main effect of light level $(\mathrm{F} 2,24=12.8 ; \quad \alpha<0.0001)$. The mean suppression values and the associated $95 \%$ confidence intervals are shown in Figure 2. Confidence intervals are used as indices of measurement uncertainty to determine if zero suppression (i.e., absolute threshold) is included in the range of uncertainty. The relationship between $\mathrm{CS}$ and $\mathrm{CL}_{\mathrm{A}}$ (equation 1) is also shown in Figure 2, but, importantly, is plotted independent of the data collected for the present experiment.

Using data obtained in study 2, paired two-tailed t-tests revealed that melatonin suppression after exposure to 60 lux was significantly less than suppression after 200 lux and 720 lux ( $\alpha=0.02$ and $\alpha=0.001$, respectively). Two-tailed, one sample t-tests showed that melatonin suppression after 60-minute exposure to 200 lux and 720 lux were significantly different than zero $(\mathrm{t}(13)=2.9 ; \alpha=0.01$ and $\mathrm{t}(13)=6.4 ; \alpha<$ 0.0001 , respectively), while suppression after $60 \operatorname{lux}(\mathrm{t}(13=0.7 ; \alpha=0.5$ for study 1 and $\mathrm{t}(13)=1.1 ; \alpha=0.3$ for study 2), 22 lux $(\mathrm{t}(13)=-1.1$; $a$ $=0.3)$, and $8 \operatorname{lux}(t(13)=0.7 ; \alpha=0.5)$ were not statistically significantly different than zero. These results from the inferential statistics are consistent with the $95 \%$ confidence interval descriptive statistics. Table 


\begin{tabular}{|l|c|c|c|c|c|c|}
\hline $\begin{array}{l}\text { Corneal } \\
\text { illuminance } \\
\text { (lux) }\end{array}$ & CLA & CS & $\begin{array}{c}\text { Mean } \\
\text { pupil } \\
\text { diameter } \\
\text { (mm) }\end{array}$ & $\begin{array}{c}\text { Mean } \\
\text { suppres- } \\
\text { sion (\%) }\end{array}$ & $\begin{array}{c}\mathbf{9 5 \%} \\
\text { confidence } \\
\text { interval (\%) }\end{array}$ & $\begin{array}{c}\text { Sample size } \\
\text { for } \boldsymbol{\alpha}<\mathbf{0 . 0 5} \\
\text { and } \boldsymbol{\beta}<\mathbf{0 . 0 5} \\
\text { (n) }\end{array}$ \\
\hline 8 & 6 & 0.01 & 6.8 & -5.8 & $-24.5-12.8$ & $386^{*}$ \\
\hline 22 & 16 & 0.02 & 6.9 & -13 & $-38.4-12.5$ & $154^{*}$ \\
\hline 60 (study 1) & 42 & 0.06 & 6.4 & 4.8 & $-10.2-19.9$ & 405 \\
\hline 60 (study 2) & 42 & 0.06 & 6.0 & -10 & $-34.3-13.9$ & $205^{*}$ \\
\hline 200 & 141 & 0.19 & 4.6 & 19 & $6.7-30.7$ & 17 \\
\hline 720 & 509 & 0.42 & 3.9 & 37 & $23.0-50.5$ & 8 \\
\hline
\end{tabular}

*Sample size need to reach statistically significant negative suppression levels.

Table 2: Corneal (photopic) illuminance levels (lux) employed in the two studies together with the associated levels of Circadian Light $\left(\mathrm{CL}_{\mathrm{A}}\right)$ and Circadian Stimulus (CS) from one-hour exposure, the measured mean pupil diameters, the measured mean levels of nocturnal melatonin suppression, the $95 \%$ confidence intervals fo the mean melatonin suppressions, and the sample sizes needed to meet a criterion probability of 0.05 for both Type I ( $\alpha$ ) and Type II $(\beta)$ errors.

\begin{tabular}{|c|c|c|c|}
\hline CS & $\mathrm{CL}_{\mathrm{A}}$ & $\begin{array}{c}\text { Corneal } \\
\text { Illuminance (lux) } \\
2670 \mathrm{~K}\end{array}$ & $\begin{array}{c}\text { Corneal Illumi- } \\
\text { nance (lux) } \\
6520 \mathrm{~K}\end{array}$ \\
\hline 0.050 & 35 & 50 & 26 \\
\hline 0.10 & 72 & 101 & 51 \\
\hline 0.15 & 110 & 156 & 79 \\
\hline
\end{tabular}

Table 3: Levels of Circadian Stimulus (CS) and Circadian Light (CLA) associated with one-hour exposures from two white light sources $(2670 \mathrm{~K}$ and $6520 \mathrm{~K})$ for different levels of corneal (photopic) illuminance (lux).

2 summarizes the empirical findings and the independent, associated model predictions.

\section{Discussion}

The present results show a dose-response characteristic for nocturnal melatonin suppression for different corneal light exposures that is consistent with the updated model predictions from Rea and colleagues [6,7]. The measured levels of light-induced nocturnal melatonin suppression obtained in the second study from one-hour exposures to 200 lux and 720 lux were very close to the calculated CS values as was the calculated CS at 60 lux from the first study. The low suppression levels for 8 lux, 22 lux, and 60 lux (study 2) were, in fact, negative, meaning that measured melatonin concentrations following one-hour exposure to these levels of light were higher than those measured in the dark. Based upon the orthodox criterion probability for a Type I error used in inferential statistics (i.e., $\alpha<0.05$ ), a one-hour exposure to 200 lux at the cornea from the "warm white," polychromatic light used in the present study was needed to reliably suppress nocturnal melatonin; obviously too, the higher level, 720 lux, was also significant at $\alpha<0.05$. The $95 \%$ confidence intervals also do not include zero suppression for the 200 lux and the 720 lux exposures, so exposure to a corneal irradiance of 200 lux (or higher) from this light source for one hour will reliably suppress nocturnal melatonin.

However, given the inherent conservative nature of inferential statistics (i.e., low $\alpha$ with an associated bias against false positives), 200 lux is probably too high a light level to be considered as a working threshold for those individuals concerned more with misses than with false positives. Specifically, many are concerned that even small amounts of suppression may lead to negative health outcomes $[32,33]$ and a working threshold of 200 lux (for one hour) would be too high because some melatonin might be suppressed. This is a legitimate concern because threshold is a construct based upon the physiological stimulus-response characteristics of a biological system in addition to perceived risk of misses and false positives [34]. Therefore, it is important to formally decide on a statistical criterion for a Type II error, the probability $(\alpha)$ of a miss, as well as the probability of a Type I error (a) when proposing a working threshold for light-induced nocturnal melatonin suppression.

Type II errors are directly related to statistical power (P), whereby $\mathrm{P}=1-\beta$ In addition to the empirical results from this study and the model predictions, Table 2 shows the sample sizes needed to reach statistical criteria of $\alpha<0.05$ and $\beta<0.05$. As can be seen, for light levels less than 200 lux, very large sample sizes would be needed to meet these stringent statistical criteria biased against both false positives and misses. Considering (a) that the uncertainty in melatonin assays are approximately $10 \%$ to $15 \%$, (b) that the two estimated suppression levels from one-hour exposure of 60 lux for this light source were within that range, and (c) that both positive suppression (study 2) and negative suppression (study 1) were observed for a one-hour exposure to $60 \mathrm{lux}$, it seems rather unlikely that a new study employing 400 subjects (or more) would, in fact, lead to a statistically reliable $(\beta<0.05$ and $\alpha<0.05$ ) level of nocturnal melatonin suppression from one-hour exposure to 60 lux from this light source. Therefore, another method for estimating a working threshold is needed, albeit one consistent with inferential statistics.

Using equation 1 and the updated model by Rea and colleagues [6], three levels of CS, $0.05,0.10$, and 0.15 , were chosen to frame considerations of a working threshold for "white" light. Two light sources were used, the one used in the present study $(2670 \mathrm{~K})$ and a 6520 K LED (Luxeon ML-PW51 [Philips Lumileds Lighting, San Jose, CA] with a diffuser [Roscolux "Tough White Diffusion" \#116, Rosco, Stamford, CT] and blue filter [Roscolux "Full Blue" \#3202, Rosco, Stamford, CT] attached). These two sources represent the entire range of electric light source CCTs manufactured and sold as "white" illumination for architectural lighting [35]. Table 3 shows the estimated photopic illuminance levels incident on the cornea for one hour that would be needed to achieve CS values of $0.05,0.10$, and 0.15 from these two light sources.

Assuming a working threshold based upon $\mathrm{CS}=0.05$, then it would take a one-hour corneal light exposure of 50 lux from the "warm white" source or of 26 lux from the "cool white" source to induce approximately $5 \%$ suppression of melatonin at night. In choosing a criterion suppression level for a working threshold of light exposure, it is necessary to consider the levels of corneal light exposures that people actually experience in their homes at night to meet their personal needs for safety, reading, watching television and socializing; a working threshold for light exposure set too low may, in fact, compromise human comfort, visual needs, and safety in the home [36].

Despite stated concerns for electric light sources in the home as they might pose health risks from melatonin suppression at night [3739], very few data have been reported concerning actual light exposures in living and working environments. Figueiro et al. [40] reviewed data collected from several studies that utilized the Daysimeter, a personal light exposure meter calibrated in terms of photopic illuminance (lux), $\mathrm{CL}_{\mathrm{A}}$, and CS. That review showed that the median of the mean photopic illuminance levels and the median of the mean CS levels for evening light exposures in five different populations (teachers, eighth grade students, young adults, day-shift nurses, and rotating-shift nurses) were 63 lux and 0.046, respectively, suggesting that, on average, evening light exposures could result in nocturnal melatonin suppression of approximately 5\%. The highest mean CS level for evening light 
Citation: Rea MS, Figueiro MG (2013) A Working Threshold for Acute Nocturnal Melatonin Suppression from "White" Light Sources used in Architectural Applications. J Carcinogene Mutagene 4: 150. doi:10.4172/2157-2518.1000150

Page 5 of 6

exposures was 0.07 , which was associated with the rotating-shift nurses who, among the groups examined here, are known to be at higher risk for breast cancer.

Depending then upon one's own perspective with regard to misses or false positives, these measured levels of evening light may or may not be considered a health risk. A great deal more data will have to be collected and analyzed (considering both false positives and misses) to establish a more precise threshold light exposure for nocturnal melatonin suppression. Nevertheless, in the public interest, it seems incumbent upon the scientific community to establish a hypothesized working threshold for light exposure at night until much more data are collected and analyzed.

Here we propose, for further testing, that the hypothesized working threshold for acute nocturnal melatonin suppression be 30 -minute exposure to a 30 lux at the cornea from "white" light sources that might be used in architectural applications. These values represent a conservative estimate of dose, recognizing that the empirical results of the present studies and the traditional probability of a Type I error (i.e., $\alpha<0.05$ ), a one-hour exposure to 200 lux from the selected "warm white" light source would be the lowest lighting condition that could reliably suppress nocturnal melatonin synthesis. Although a lower exposure level could be considered as the working threshold, it should be recalled that 60 lux did not reliably suppress melatonin in either of the two studies. Given our own concerns for health risk and our field measurements of actual light exposures in the home $[40,41]$ we believe that a one-hour exposure to even 60 lux of "white" light is too high as a working threshold. Rather, given (a) the consistency between the empirical results presented here and the model predictions of CS (Figure 2), (b) the field measurements of actual light exposures [40,41], and (c) our own concerns for public health (i.e., a bias against misses), we concluded that our earlier proposal of 30 lux for 30 minutes from "white" light can still be used as a working threshold for lightinduced nocturnal melatonin suppression. This exposure level should limit, on average, nocturnal melatonin suppression to less than $5 \%$ (i.e., CS $<0.05$ ), a value within the uncertainty of measuring melatonin concentrations using current radioimmunoassay methods.

The present results are relevant for the discussion about LAN as an endocrine disruptor. The incidence of breast cancer has continuously increased in modern industrialized society and is the most frequently diagnosed malignant disease in women of all ethnic groups in the United States and Northern Europe. The reasons for this increase in breast cancer incidence are still unknown, but it is well accepted that breast cancer risk is affected by endogenous factors, such as the concentration levels of melatonin, estrogen, testosterone, and insulin-growth factors (IGF). An important consideration for understanding the increased incidence of breast cancer is the disruption of regular circadian rhythms associated with living in a modern society. Disruption to the circadian cycle, either by melatonin depletion or by irregular light/ dark cycles, has been shown to increase tumor growth and mortality in animal models [42-46]. Therefore, further investigating the threshold for acute melatonin suppression and disruption of circadian rhythms is an important first step towards better understanding the effects of LAN on diseases.

\section{Acknowledgements}

The authors would like to thank Andrew Bierman, Dennis Guyon, Robert Hamner, Sharon Lesage, Anna Lok, Ines Martinovic, Barbara Plitnick, and Brittany Wood from the Lighting Research Center for their support. This research was supported by the Office of Naval Research (grant \# N00014-11-1-0572) and the Engineering Research Centers Program of the National Science Foundation under
NSF Cooperative Agreement No. EEC-0812056, in part by New York State under NYSTAR contract C090145.

\section{References}

1. Schernhammer ES, Laden F, Speizer FE, Willett WC, Hunter DJ, et al. (2001) Rotating night shifts and risk of breast cancer in women participating in the nurses' health study. J Natl Cancer Inst 93: 1563-1568.

2. Tynes T, Hannevik M, Andersen A, Vistnes Al, Haldorsen T (1996) Incidence of breast cancer in Norwegian female radio and telegraph operators. Cancer Causes Control 7: 197-204

3. Davis S, Mirick DK, Stevens RG (2001) Night shift work, light at night, and risk of breast cancer. J Natl Cancer Inst 93: 1557-1562.

4. Hansen J (2001) Increased breast cancer risk among women who work predominantly at night. Epidemiology 12: 74-77.

5. Figueiro MG, Lesniak NZ, Rea MS (2011) Implications of controlled shortwavelength light exposure for sleep in older adults. BMC Res Notes 4: 334.

6. Rea MS, Figueiro MG, Bierman A, Hamner R (2012) Modeling the spectral sensitivity of the human circadian system. Light Res Tech 44: 386-396.

7. Rea MS, Figueiro MG, Bullough JD, Bierman A (2005) A model of phototransduction by the human circadian system. Brain Res Brain Res Rev 50: $213-228$

8. Brainard GC, Hanifin JP, Greeson JM, Byrne B, Glickman G, et al. (2001) Action spectrum for melatonin regulation in humans: evidence for a novel circadian photoreceptor. J Neurosci 21: 6405-6412.

9. Thapan K, Arendt J, Skene DJ (2001) An action spectrum for melatonin suppression: evidence for a novel non-rod, non-cone photoreceptor system in humans. J Physiol 535: 261-267.

10. West KE, Jablonski MR, Warfield B, Cecil KS, James M, et al. (2011) Blue light from light-emitting diodes elicits a dose-dependent suppression of melatonin in humans. J Appl Physiol 110: 619-626.

11. Deacon S, Arendt J (1994) Posture influences melatonin concentrations in plasma and saliva in humans. Neurosci Lett 167: 191-194.

12. Smith KA, Schoen MW, Czeisler CA (2004) Adaptation of human pinea melatonin suppression by recent photic history. J Clin Endocrinol Metab 89 3610-3614.

13. Hébert M, Martin SK, Lee C, Eastman Cl (2002) The effects of prior light history on the suppression of melatonin by light in humans. J Pineal Res 33: 198-203.

14. Arendt J, Skene DJ (2005) Melatonin as a chronobiotic. Sleep Med Rev 9 25-39.

15. Herljevic M, Middleton B, Thapan K, Skene DJ (2005) Light-induced melatonin suppression: age-related reduction in response to short wavelength light. Exp Gerontol 40: 237-242.

16. Peuhkuri K, Sihvola N, Korpela R (2012) Dietary factors and fluctuating levels of melatonin. Food Nutr Res 56

17. Berson DM, Dunn FA, Takao M (2002) Phototransduction by retinal ganglion cells that set the circadian clock. Science 295: 1070-1073.

18. Dacey DM, Packer OS (2003) Colour coding in the primate retina: diverse cell types and cone-specific circuitry. Curr Opin Neurobiol 13: 421-427.

19. Figueiro MG, Rea MS, Bullough JD (2006) Does architectural lighting contribute to breast cancer? J Carcinog 5: 20.

20. Mclntyre IM, Norman TR, Burrows GD, Armstrong SM (1989) Human melatonin suppression by light is intensity dependent. J Pineal Res 6: 149-156.

21. Rea MS, Bullough JD, Figueiro MG (2001) Human melatonin suppression by light: a case for scotopic efficiency. Neurosci Lett 299: 45-48.

22. Figueiro MG, Rea MS, Bullough JD (2006) Circadian effectiveness of two polychromatic lights in suppressing human nocturnal melatonin. Neurosci Lett 406: 293-297.

23. Jean-Louis G, Kripke DF, Elliott JA, Zizi F, Wolintz AH, et al. (2005) Daily illumination exposure and melatonin: influence of ophthalmic dysfunction and sleep duration. J Circadian Rhythms 3: 13.

24. Charman WN (2003) Age, lens transmittance, and the possible effects of light on melatonin suppression. Ophthalmic Physiol Opt 23: 181-187. 
Citation: Rea MS, Figueiro MG (2013) A Working Threshold for Acute Nocturnal Melatonin Suppression from "White" Light Sources used in Architectural Applications. J Carcinogene Mutagene 4: 150. doi:10.4172/2157-2518.1000150

Page 6 of 6

25. Lynch HJ, Deng MH, Wurtman RJ (1985) Indirect effects of light: ecological and ethological considerations. Ann N Y Acad Sci 453: 231-241.

26. Roenneberg T, Wirz-Justice A, Merrow M (2003) Life between clocks: daily temporal patterns of human chronotypes. J Biol Rhythms 18: 80-90.

27. Bullough JD, Brons JA, Qi R, Rea MS (2008) Predicting discomfort glare from outdoor lighting installations. Light Res Tech 40: 225-242.

28. ANSI/IESNA Recommented Practice for Photobiological Safety for Lamps \& Lamp SystemsGeneralRequirements.http://webstore.ansi.org/RecordDetail.as px?sku=ANSI\%2FIESNA+RP-27.1-05

29. Rea MS, Figueiro MG, Bierman A, Bullough JD (2010) Circadian light. J Circadian Rhythms 8: 2.

30. Brainard GC, Sliney D, Hanifin JP, Glickman G, Byrne B, et al. (2008) Sensitivity of the human circadian system to short-wavelength $(420-\mathrm{nm})$ light. J Bio Rhythms 23: 379-386.

31. Zeitzer JM, Dijk DJ, Kronauer R, Brown E, Czeisler C (2000) Sensitivity of the human circadian pacemaker to nocturnal light: melatonin phase resetting and suppression. J Physiol 526 Pt 3: 695-702.

32. Stevens RG (2009) Light-at-night, circadian disruption and breast cancer: assessment of existing evidence. Int J Epidemiol 38: 963-970.

33. Chepesiuk R (2009) Missing the dark: health effects of light pollution. Environ Health Perspect 117: A20-27.

34. SWETS J, TANNER WP Jr, BIRDSALL TG (1961) Decision processes in perception. Psychol Rev 68: 301-340.

35. ANSI (2008) American National Standard for Electric Lamps: Specifications for the Chromaticity of Solid State Lighting Products. vol C78.377. National Electric Manufacturers Association, Rosslyn, VA
36. Figueiro MG (2008) A proposed $24 \mathrm{~h}$ lighting scheme for older adults. Light Res Tech 40(2):153-160.

37. Stevens RG (2005) Circadian disruption and breast cancer: from melatonin to clock genes. Epidemiology 16: 254-258.

38. Stevens RG, Rea MS (2001) Light in the built environment: potential role of circadian disruption in endocrine disruption and breast cancer. Cancer Causes Control 12: 279-287.

39. Stevens RG, Blask DE, Brainard GC, Hansen J, Lockley SW, et al. (2007) Meeting report: the role of environmental lighting and circadian disruption in cancer and other diseases. Environ Health Perspect 115: 1357-1362.

40. Figueiro MG, Hamner R, Higgins P, Hornick T, Rea MS (2012) Field measurements of light exposures and circadian disruption in two populations of older adults. J Alzheimers Dis 31: 711-715.

41. Rea MS, Brons JA, Figueiro MG (2011) Measurements of light at night (LAN) for a sample of female school teachers. Chronobiol Int 28(8): 673-680.

42. Blask DE, Dauchy RT, Sauer LA (2005) Putting cancer to sleep at night: the neuroendocrine/circadian melatonin signal. Endocrine 27: 179-188.

43. Filipski E, Delaunay F, King VM, Wu MW, Claustrat B, et al. (2004) Effects of chronic jet lag on tumor progression in mice. Cancer Res 64: 7879-7885.

44. Filipski E, Li XM, Lévi F (2006) Disruption of circadian coordination and malignant growth. Cancer Causes Control 17: 509-514.

45. Fu L, Lee CC (2003) The circadian clock: pacemaker and tumour suppressor. Nat Rev Cancer 3: 350-361.

46. Fu L, Pelicano H, Liu J, Huang P, Lee C (2002) The circadian gene Period2 plays an important role in tumor suppression and DNA damage response in vivo. Cell 111: 41-50. 